\title{
LA CONSTRUCCION SOCIAL DEL CUERPO DE LA MUJER EN EL DEPORTE ${ }^{1}$
}

\author{
Ana Buñuel Heras
}

Ayuntamiento de Madrid

\section{INTRODUCCION}

La escasa producción de estudios de carácter sociológico en torno al cuerpo en la comunidad científica española, sobre todo en los aspectos relacionados con el ejercicio físico y el deporte, confirma la dicotomía clásica entre la mente y el cuerpo, separación que ha tenido como consecuencia un distanciamiento intelectual hacia todo lo que significaba corporeidad. Esta paradoja sigue produciéndose en una sociedad como la actual, donde el cuerpo es un valor central, es un signo de status y un símbolo de éxito o fracaso, un vehículo mediático para la venta de los más variados productos.

Según B. S. Turner (1989), el estudio del cuerpo es de «genuino interés sociológico», al ser «la característica más próxima e inmediata de mi yo social, un rasgo necesario de mi situación social y de mi identidad personal, y a la vez un aspecto de mi alienación personal en el ambiente natural». Como afirma este autor, el cuerpo debe ser considerado como problema central de la teoría social contemporánea por varias razones: en primer lugar, el pensamiento feminista ha "puesto sobre el tapete» el tema del cuerpo al criticar el determi-

Esta investigación constituyó la Tesis Doctoral de la autora, presentada, en 1991, en la Facultad de Ciencias Políticas y Sociología de la Universidad Complutense de Madrid, y dirigida por la Catedrática doña. M. Angeles Durán. 
nismo del cuerpo sexuado y replantear el problema de la discriminación en términos de género; en segundo lugar, el cuerpo es el objetivo de un amplio mercado de consumidores, en su reproducción, su representación y sus procesos; en tercer lugar, las modificaciones en la medicina (aparición de medicinas alternativas) que conllevan una redefinición del propio concepto de enfermedad y la relación con el cuerpo; en cuarto lugar, la secularización actual del cuerpo, que facilita su mercantilización; y, por último, la creciente importancia política de la ecología, la supervivencia (lo que denomina Turner el cambio del debate político «de rojo a verde»).

En las sociedades industriales avanzadas se observa el auge de nuevos valores, como son la libertad sin restricciones, el reforzamiento del yo individual, rechazo de la disciplina; en general, una mayor preocupación por la calidad de vida frente a las preocupaciones fundamentalmente económicas de las sociedades industrializadas, como señala D. Bell (1980). Se trata de lo que R. Inglehart (1991) denomina la emergencia de valores "postmaterialistas», entre los que se encuentran la autoexpresión y la calidad de vida, asumidos por una nueva clase social y que van extendiéndose en los diferentes estratos sociales y generacionales de nuestra sociedad.

El protagonismo social del cuerpo viene impulsado hoy por varios elementos: la progresiva secularización de la sociedad moderna, que rechaza el concepto de la salud como don divino o de la naturaleza (Krawczyk, 1983) y, al mismo tiempo, el cuerpo moderno pierde la connotación negativa de cuerpopecado, cuerpo-condenación, para acercarse más a la de cuerpo-salvación, cuerpo-redención. El carácter mercantilista de la sociedad actual, donde el cuerpo pasa a "cotizarse» como un objeto de consumo más, lleva a los individuos a «invertir», tiempo y dinero, en apariencia y estado de salud.

Hoy en día, donde puede decirse que las necesidades básicas están resueltas para la mayoría de la población en las sociedades industriales avanzadas, cobran relevancia necesidades relacionadas con la mejora de la calidad de vida: mantenimiento y mejora del estado de salud, ocupación del tiempo libre en actividades lúdico-culturales, etc. Esta es una de las principales explicaciones al auge que las actividades físico-deportivas han experimentado en la sociedad española en los últimos quince años.

Como señala M. García Ferrando (1982, 1986, 1990, 1991), autor de numerosos análisis sobre el significado social del deporte, el creciente interés por el mismo está relacionado con necesidades tan variadas como el rechazo al sedentarismo y a la rutina de la vida cotidiana, la necesidad de pertenencia a un grupo — donde haya una coincidencia de aficiones y gustos_-, la búsqueda de salud y esparcimiento, o la identificación con ciertas prácticas socioculturales. Asimismo, afirma la necesidad del análisis social del cuerpo humano para comprender el deporte contemporáneo (1990).

D. Bell (1976), en su libro Las contradicciones culturales del capitalismo, señalaba que el principio axial de la cultura moderna es la expresión y la remodelación del "yo» para lograr la autorrealización. Dentro del amplio abanico de 
actividades existentes hoy en día que conducen a dicha autorrealización se encuentran las actividades físico-deportivas. La actividad físico-deportiva recreativa se caracteriza por ser una ocupación voluntaria, un descanso con respecto a las demás actividades, e implica diversión, formación, participación social, desarrollo de la capacidad creadora y recuperación psicofísica (J. M. Cagigal, 1981).

Como habrá observado el lector, se han utilizado indistintamente los términos deporte y prácticas físico-deportivas refiriéndonos al mismo concepto. Desde hace algunos años, viene discutiéndose el significado del término "deporte», ya que, por su extraordinaria polisemia, puede incluir desde el simple paseo $^{2}$ a las actividades físicas extremadamente regladas del deporte de alta competición.

En los trabajos más recientes de Sociología del Deporte, el deporte es definido como «sistema abierto" y «cambiante» (Heinemann, 1991; y García Ferrando, 1991), y se insiste en sus interrelaciones con el entorno físico, la tecnología, los valores e imágenes sociales, el mundo económico y financiero, etcétera, que confiere a su estudio una multidimensionalidad que es necesario contemplar.

Según la teoría «desarrollista» de Norbert Elias (1992) aplicada al estudio del ocio y el deporte, las actividades deportivas suponen un escape al alto nivel de autocontrol que exigen las sociedades desarrolladas, como un remedio para las tensiones que ellas mismas generan. Muchas actividades recreativas proporcionan un escenario ficticio para experimentar emociones que ya no se encuentran en otras actividades cotidianas.

En este estudio, nos referiremos a unas prácticas físico-deportivas (preferimos utilizar este término, ya que todavía la palabra "deporte» se asocia más frecuentemente con el deporte de competición ) de carácter recreativo, las gimnasias "de la forma»", que han experimentado una gran difusión desde los años ochenta en la sociedad española, como en otras sociedades industriales avanzadas. Bajo la denominación "gimnasias de la forma" incluimos una serie de actividades físicas: gimnasia de mantenimiento, aerobic, gim-jazz, musculación y yoga, que tienen como principal rasgo común el interés de sus practicantes por mantener o mejorar tanto la salud como la apariencia física.

El fenómeno de las gimnasias "de la forma» nos permite, dentro del estudio sociológico de las prácticas corporales, un análisis en cierto modo paradigmático; en ellas confluyen varios aspectos de gran interés, como son la crecien-

2 En los estudios sociológicos sobre comportamiento deportivo tiende, cada vez más, a incluirse bajo la denominación de deporte un conjunto más amplio y variado de actividades, que abarcan desde el paseo — practicado de forma cotidiana — a actividades deportivas muy regladas y competitivas.

3 La denominación "de la forma» hace referencia al objetivo general de estas prácticas que, fundamentalmente, consiste en el mantenimiento y mejora de la "forma física», concepto que tiene un contenido tanto físico como psicológico y social. En el texto se utilizan indistintamente los términos gimnasias de la forma y gimnasias recreativas para referirnos a las mismas actividades. 
te importancia de los servicios alrededor del cuerpo, la influencia de los medios de comunicación, la discusión en torno a deporte y género (deportes femeninos/deportes masculinos), y el auge de las actividades físico-deportivas de carácter flexible frente al deporte federativo, entre otros.

Otro concepto que precisa alguna matización es el significado que el ocio tiene en nuestra sociedad actual. El tiempo de trabajo, en general, ha disminuido considerablemente; las actividades culturales, con la democratización cultural anteriormente citada, pasan a rellenar gran parte de ese tiempo de ocio. Según el clásico estudio de Dumazedier (1964), el ocio cumple fundamentalmente tres funciones: relajación, diversión y desarrollo de la propia personalidad. No obstante, estamos asistiendo a una regulación del tiempo libre por analogía del tiempo de trabajo, pasando a constituir, como señala E. Gil Calvo (1985), una «inversión económica, realizada con la esperanza matemática de alcanzar ulteriormente un beneficio». Y, podría añadirse, «inversión en uno mismo" mediante un consumo importante de productos y actividades.

Existen varias razones para el interés creciente por el deporte y la actividad fisica como forma de ocio: el ya citado aumento del tiempo libre por la reducción de la jornada de trabajo, la condición física como parte esencial del buen estado de salud y mayor longevidad, las necesidades estéticas de las personas, y la presión de los medios de comunicación, sobre todo en zonas urbanas.

No obstante, resulta imprescindible añadir en nuestro análisis un nuevo elemento: el concepto de género, en este caso aplicado al diferente significado del tiempo libre para varones y mujeres. Para los primeros, los tiempos están claramente delimitados y permiten su estructuración y la práctica de actividades organizadas. Para las mujeres, y sobre todo para las amas de casa, que, recordemos, siguen siendo la mayoría de las mujeres españolas, el tiempo libre es residual y fragmentario (M.a A. Durán, 1987), lo que dificulta su participación en actividades exteriores al hogar y con horarios determinados.

Estas diferencias sociales entre varones y mujeres asimismo se hacen patentes cuando analizamos sociológicamente la producción y utilización del cuerpo. Persisten hoy en día ciertas desigualdades en la consideración del cuerpo en ambos géneros. Según B. Vázquez (1987), mientras que para los varones el cuerpo es "potencial de acción", cuerpo para sí mismo, orientado hacia el exterior, la mujer «vive su cuerpo en función de los demás», para el varón (función tradicional de seducción), para los hijos (función biológica de la maternidad); en definitiva, con un cierto carácter de «bien social». Esta concepción tradicional del cuerpo femenino ha sido fuertemente criticada por el Movimiento Feminista desde sus orígenes modernos a finales de los años sesenta, reclamando para la mujer el derecho a decidir sobre su propio cuerpo, sobre la maternidad, sobre la sexualidad, sobre la apariencia ${ }^{4}$.

4 Un exponente de esta postura se encuentra en el libro Nuestros cuerpos, nuestras vidas, del Colectivo del Libro de la Salud de las Mujeres de Boston, versión española en Ed. Icaria, 1982. 


\section{EL ANALISIS SOCIOLOGICO SOBRE LA PRODUCCION SOCIAL DEL CUERPO}

Las reflexiones culturales sobre el cuerpo en nuestro siglo se han situado, por encima de otros, en el campo filosófico y antropológico. Se cita al antropólogo Marcel Mauss como precursor de la reflexión social sobre el cuerpo en su artículo "Las técnicas del cuerpo» (1966), donde sienta las bases de la consideración social de las prácticas corporales. Muestra cómo para comprender la educación del cuerpo es necesario aunar los esfuerzos de la sociología con la biología y la psicología. El cuerpo, señala, es a la vez el primero y el más natural instrumento, así como objeto técnico. El cuerpo es considerado un producto cultural, con diferentes usos según sociedades y con diferentes valores, creencias y cánones estéticos asociados a él. Así pues, este cuerpo es moldeado por la organización social y llega a ser «signo» de la pertenencia social, de la posición dentro del orden social.

En un intento de analizar diferentes aportaciones relevantes sobre la producción social del cuerpo, agruparemos éstas en tres grandes bloques:

- Un primer discurso que considera el cuerpo como mercancía, como objeto de consumo y a la vez signo (y donde las aportaciones más significativas se deben a autores como Baudrillard, 1974; Boltanski, 1971; Bourdieu, 1979).

- Una segunda teoría sobre el cuerpo como lenguaje, como sistema semiológico que funciona para el sujeto como productor de sentido, y que se dirige a otros actores a través del gesto (desarrollado por Birdwhistell, 1972); encontrando un interesante precedente en la obra El hombre y la gente (Ortega y Gasset, 1934).

- Y un tercer bloque de análisis sobre el cuerpo como dominación, lugar de control, de opresión (desarrollado por Foucault, 1984, y en otro contexto, por el pensamiento feminista).

\section{El cuerpo, signo y mercancía en la sociedad de consumo}

Por su impacto sociológico y hasta cierto punto precursor - hay que tener en cuenta que estos análisis son relativamente recientes: años setenta y ochenta-, es relevante el análisis que J. Baudrillard realiza sobre el cuerpo en su obra La sociedad de consumo (1974). Para Baudrillard, la lógica del consumo en las sociedades contemporáneas es una lógica de consumo de signos. El cuerpo aparece dentro del «abanico del consumo»: llamadas narcisistas a la reapropiación del propio cuerpo que difunde la prensa femenina, la omnipresencia del tema de la belleza, el exotismo, y, en otro registro, la forma, la línea, constituyen, según él, un proceso de «sacralización del cuerpo como valor exponencial». Lo importante es que el cuerpo parece haber sustituido al alma como objeto de salud, y que, al ser considerado como objeto de inversión (tanto eco- 
nómica como psíquica), se convierte en el instrumento de una retórica generalizada. El cuerpo en su "puesta en escena» actual funciona según las leyes de la economía política del signo: el individuo debe tomarse a sí mismo como objeto, como "el más bello de los objetos», para que pueda instituirse un proceso económico de rentabilidad. Las estructuras actuales de producción/consumo proporcionan al individuo una doble representación de su cuerpo: como capital y como fetiche, y el cuerpo moderno se exhibe en esta doble faceta de inversión y signo social.

También dentro del marco teórico de estudio de las prácticas sociales en la "sociedad de consumo" se sitúa el trabajo de M. Featherstone (1982, 1987). En sus artículos sobre el cuerpo y el ejercicio físico en la sociedad actual, considera que hay que distinguir dos tipos de exigencias con respecto al cuerpo: que el cuerpo interior (inner body) funcione bien (esté sano y "en forma») y que la apariencia (outer body) sea cuidada. Así, el cuerpo es un «signo», un "mensaje» que habla de su propietario. Por otro lado, las imágenes transmitidas por los medios de comunicación refuerzan un estilo de vida donde el cuidado del cuerpo (no sólo ejercicio físico, sino la cosmética, el vestido...) tiene un lugar central. El "prestigio" de que goza este estilo de vida hace que se adhieran a estas prácticas personas que buscan en ellas un cauce de movilidad ascendente en la estructura social. Como señala Featherstone (1982), reconocen en el cuerpo una de las pocas áreas donde todavía los individuos pueden ejercer un control cotidiano (a través del ejercicio físico, entre otros instrumentos), y no depende, como las cuestiones económicas o políticas, de instancias que se perciben ajenas.

Otro conjunto de análisis sobre los usos sociales del cuerpo provienen de la sociología francesa: P. Bourdieu y L. Boltanski. Data de 1971 un artículo de L. Boltanski sobre la dimensión social de los comportamientos corporales. En él analiza la idea de que las reglas que determinan las conductas físicas de los sujetos sociales son el producto de las condiciones objetivas de su existencia que se traducen en el orden cultural, y así condicionan la forma de comportarse. Este autor define el "hábito corporal» de los miembros de un grupo como un sistema de normas muy arraigadas, que, aunque no se expresen en su totalidad de forma sistemática, organizan implícitamente la relación de los individuos del mismo grupo social con sus cuerpos, de forma que su cultura somática presenta una unidad profunda. Y así, el cuerpo, al igual que otros objetos técnicos cuya posesión marca la posición de los individuos en la jerarquía social, es un signo de estatus con un fuerte significado simbólico, mayor cuanto que no es percibido como tal.

Señala Boltanski que el aumento de conciencia del cuerpo, que suele entenderse como el «resultado de una especie de cruzada contra los tabúes religiosos o sociales» que permite la reconquista del propio cuerpo, puede a su vez describirse como el resultado de un "proceso objetivo de desposesión cultural», ya que se corresponde con un aumento del número de «especialistas» del cuerpo y de los consejos y reglas que éstos dictan, difunden y venden. 
P. Bourdieu (1979), en su obra La distinción, profundiza en este análisis y lo lleva a sus últimas consecuencias. El cuerpo y sus diferentes usos se integran en un esquema explicativo global que relaciona, de un modo determinista, las condiciones sociales de existencia, el hábito, el gusto y el estilo de vida. Las formas de existencia objetivas condicionan el habitus, que a su vez produce un sistema de esquemas de percepción y de generación de prácticas que delimitan un estilo de vida concreto. Los estilos de vida son sistemas de signos socialmente calificados (como «distinguidos», "vulgares»). Así pues, Bourdieu define el habitus como una «disposición general» que organiza la percepción del mundo social, y es a su vez "producto de la incorporación de la división de clases sociales». La manera de tratar el cuerpo, de modelarlo, de nutrirlo, es reveladora del habitus y, en consecuencia, de la clase social de pertenencia.

La representación social del propio cuerpo es también fruto de la aplicación de un sistema de enclasamiento social; el «esquema corporal» es el depositario de esta visión del propio cuerpo, del de los otros y del mundo social.

La apariencia o aspecto exterior como idea central de la representación del cuerpo está ligada al concepto del cuerpo como «valor», valor intercambiable. El interés por el aspecto está así directamente relacionado con las oportunidades del provecho material o simbólico que pueda proporcionar. Bourdieu señala que las clases populares, que se supone ocupan menos puestos que implican relaciones públicas, tienen menos conciencia del valor comercial de la belleza y de la representación, y por ello están menos dispuestos a invertir en ellas tiempo y dinero.

Bourdieu, en su obra Les sens pratique (1980), profundiza en el análisis antropológico de la relación entre el cuerpo y el habitus. El «sentido práctico», como principio de aplicación del habitus al campo de las prácticas, sólo existe en tanto que incorpora y pone en práctica los esquemas de percepción y de acción en los que «el cuerpo es a la vez el soporte, el agente y la expresión». Los esquemas de percepción se enraizan en la división social y sexual del trabajo y generan clasificaciones binarias que definen los géneros masculino y femenino. Lo que se aprende con el cuerpo «no es algo que se tiene, sino que se es».

\section{El cuerpo como instrumento de lenguaje en la interacción social}

Un interesante precedente de estos estudios lo encontramos en Ortega y Gasset, en una breve referencia dentro de Lecciones sobre el hombre y la gente (1957), y especialmente en su ensayo Sobre la expresión, fenómeno cósmico (1934). Ya entonces, Ortega y Gasset afirmaba que el "cuerpo del otro es un abundantísimo semáforo que nos envía constantemente las más variadas señales o indicios o barruntos de lo que pasa en el "dentro" que es el otro hombre». Este autor resalta la función expresiva del cuerpo, que transmite señales al «otro» y es así elemento comunicador.

Esta teoría ha sido desarrollada más recientemente por la llamada «Escuela 
de Filadelfia», y esencialmente por los autores R. Birdwhistell (1972) y E. Goffman (1981).

R. Birdwhistell, partiendo de la lingüística estructural y de la teoría cibernética de la interacción (feed-back, etc.), propone una nueva aproximación teórica de los «micromovimientos» corporales. A este estudio cultural-comunicacional del movimiento corporal se le denomina «Kinésica» (Kinesics), donde el cuerpo se estudia como contexto de la comunicación. Los movimientos y gestos corporales adoptan formas y estructuras determinadas culturalmente, fruto de un aprendizaje social (socialización). Birdwhistell estudia y desmenuza escrupulosamente los "microgestos», y reconstruye así la estructura del movimiento (etología o antropología visual) para conocer su sentido en un momento determinado a través del análisis del contexto: quién realiza un determinado movimiento, dónde, cuándo y dentro de qué interacciones. Este autor considera el comportamiento corporal como algo fruto del aprendizaje sociocultural.

Más conocido nos resulta el otro autor al que hacemos referencia: E. Goffman, que desarrolla una sociología centrada en las condiciones sociales de la interacción, del «encuentro», donde el cuerpo ocupa un lugar central como soporte entre lo individual y lo colectivo. Según Goffman, los individuos, mediante el cuerpo, pueden definir sistemas de valores que sirven de esquemas para determinar las conductas a adoptar en diferentes situaciones. Mediante el estudio meticuloso del gesto, de la mirada, de las posturas, Goffman construye una «Etología de la interacción». Define ésta como «la influencia recíproca del individuo sobre las acciones del otro cuando se encuentran ambos en presencia física inmediata». La "fachada», o modo de presentación de un individuo, está compuesta por la "apariencia» (appearance), que da información sobre el status social del actuante, y por los «modales» (manner), que lo hacen sobre el rol de interacción que éste espera desempeñar en la situación. Cuando describe las reglas de comportamiento en diferentes situaciones, las normas de vestido y de presentación de uno mismo, tiene en cuenta toda la relación del cuerpo con su ambiente social y material. Así, el cuerpo aparece como envoltura, como lugar de estrategias de aproximación o de fuga, como territorio.

Este último elemento, el territorio, ha sido analizado por Edward T. Hall (1973) en su obra sobre el espacio y la distancia como dimensión de la regulación de las interacciones sociales. Sin entrar más en su teoría, la "proxémica», señalaremos la importancia y la novedad de estudiar el funcionamiento social de la distancia física entre los cuerpos. Hall distingue entre distancia íntima, distancia personal y distancia pública, tres categorías teóricas y prácticas que están delimitadas culturalmente y que pueden aplicarse al análisis de la relación entre individuos en espacios cerrados (como el gimnasio). 


\section{La política del cuerpo: los cuerpos como lugar de poder}

Bajo este epígrafe consideraremos las aportaciones de M. Foucault (1975, 1984) (sobre todo Vigilar y castigar), las reflexiones de J. M. Brohm (1982), y el discurso feminista sobre el cuerpo - la dominación patriarcal del cuerpo de la mujer-.

Foucault, desde una perspectiva estructuralista, estudia en varias de sus obras más relevantes el origen de las instituciones y cómo, a través de ellas, se ejerce el control de los cuerpos y, por lo tanto, de las personas. En el segundo volumen de la Historia de la Sexualidad («El uso de los placeres»), Foucault analiza los discursos prescriptivos sobre la conducta sexual en los textos griegos clásicos. En este estudio queda patente el «componente social» de las conductas corporales, en este caso sexuales, y cómo ya en los griegos existía una ética o moral sexual que prescribía la forma de vivir "más armoniosa posible». No obstante, es en la obra Vigilar y castigar. Nacimiento de la prisión donde Foucault centra su problemática en el cuerpo, avanzando la idea de una "política del cuerpo». A través de las cuatro partes en que se divide la obra - suplicio, castigo, disciplina y prisión-, analiza «la metamorfosis de los métodos punitivos a partir de una tecnología política del cuerpo donde pudiera leerse una historia común de las relaciones de poder y de las relaciones de objeto». Cuando se desarrolla la disciplina como arte de "hacer obediente» al cuerpo humano en las instituciones militares, médicas, escolares e industriales, se constituye lo que el autor demonina la «microfísica del poder», que analiza la distribución de los individuos en el espacio (zonas, rangos...), así como el control del empleo de tiempo y el gesto eficaz.

Desde la perspectiva del materialismo histórico, Jean-Marie Brohm (1982), sociólogo crítico del deporte, ha desarrollado su reflexión sobre la "condición política del cuerpo». Según este autor, el humanismo del cuerpo que vivimos en la actualidad no es más que una expresión de las exigencias del sistema capitalista. Así pues, el hombre seguiría siendo un apéndice de la máquina (en términos de Marx), ya que la lógica del cuerpo sigue siendo la lógica del rendimiento. Brohm habla de un doble proceso de «sublimación represiva», o proceso de sometimiento del individuo mediante la represión de los instintos, y de "desublimación represiva», donde las satisfacciones acordadas (el erotismo, el exhibicionismo del cuerpo, el ejercicio corporal) son satisfacciones «sustitutas» totalmente integradas en el orden establecido. Se trata, según él, de elementos pseudoliberadores (un «nuevo opio») que no modifican la condición fundamental que procurará la libertad a los individuos.

De otra índole son los análisis críticos que diversas autoras feministas han realizado sobre la utilizacion del cuerpo de las mujeres como objetos, signos, mercancías, en la sociedad actual. El Movimiento Feminista ha desarrollado en diferentes países una reflexión sobre el cuerpo de la mujer objeto de represión, de escándalo, de explotación, y sobre los mitos de impureza en la mujer desde el cristianismo y el judaísmo. En este sentido, desde algunas corrientes femi- 
nistas se reivindica la elaboración, por parte de las mujeres, de un nuevo lenguaje corporal'5.

M. A. Durán estudia en su obra De puertas adentro (1988) la discrepancia genérica en el conocimiento y uso del propio cuerpo. El cuerpo es, por excelencia, lugar de cultura, de socialización, con normas distintas para cada uno de los géneros. Como señala la autora, «las normas que se refieren al cuerpo de las mujeres son más estrictas y móviles que las referidas al cuerpo de los hombres, precisamente por su definición cultural de cuerpo/objeto o cuerpo deseado». El cuerpo de las mujeres debe ser bello y al mismo tiempo fértil; es, sobre todo, un cuerpo para los demás, aunque, como también señala Durán, este modelo ya no es el único existente: ahora se dan, junto a este modelo tradicional de mujer, sobre todo en las generaciones más jóvenes, otras normas de comportamiento corporal caracterizadas por el individualismo y la búsqueda del bienestar personal.

\section{EXPLICACIONES SOCIOLOGICAS DE LAS GIMNASIAS RECREATIVAS}

Desde finales de los años sesenta tiene lugar un cambio social importante en España, fruto de la progresiva industrialización, la apertura hacia otros países del entorno occidental y la llegada del turismo masivo a España.

Todo ello ha propiciado un cambio de valores, entre ellos una progresiva secularización, deseo de realización personal, importancia de la apariencia física, y que, consecuentemente, han influido en un cambio en la imagen social del cuerpo y su consideración moral. También en este sentido las gimnasias se «secularizan", perdiendo ese carácter moral y en gran parte represor, para pasar a ser una actividad cultural de masas, dentro de una nueva concepción del tiempo libre y relacionado con lo que G. Lipovetsky (1983) denomina el «hedonismo individual». Así, las gimnasias cobran una relevante actualidad, según nuestro entender, desde el momento en que giran alrededor del «cuerpo moderno", un cuerpo protagonista que se modela, se mantiene saludable o busca su salud, se equilibra-con-la-mente, se expresa a través del movimiento.

En los últimos años, varios autores se han interesado, desde diferentes marcos teóricos, por el estudio sociológico de las prácticas gimnásticas en el mundo moderno.

En la sociología francesa destacan dos posturas en cierto modo enfrentadas. Por un lado, P. Bourdieu (1979), con su teoría sobre la relación existente entre la lógica "de la distinción" y las prácticas culturales en nuestra sociedad. Por otro, el sociólogo G. Lipovetsky (1983), con su enfoque del «hedonismo cultural» actual.

En la sociología norteamericana, las gimnasias «de la forma» han sido estu-

${ }^{5}$ Véase Luce Irigaray (1977), Ce sexe qui n'en est pas un, en Ed. de Minuit, París. 
diadas fundamentalmente desde dos perspectivas teóricas. En primer lugar, la interaccionista-simbólica (B. Johnson y B. Philips, 1985; A. Klein, 1986; W. E. Thompson y J. H. Bair, 1982), que analiza dichas prácticas en términos de «subcultura» de la forma; y, en segundo lugar, utilizando una comparación o "metáfora» religiosa. Es decir, se analizan los elementos de las gimnasias que permiten compararlas con una «nueva religión» (Edgely y Turner, 1982).

Según P. Bourdieu (1979), el habitus, o "disposición general» de la persona, derivado de las condiciones objetivas de su existencia, y producto de la división de clases sociales, organiza su percepción del mundo social. El habitus conlleva un sistema de esquemas de percepción y de generación de prácticas que condicionan un estilo de vida determinado. Así pues, la manera de tratar el cuerpo, de modelarlo, revela el habitus, y, por lo tanto, la clase social de pertenencia.

Siguiendo con este razonamiento, Bourdieu afirma que la apariencia exterior está ligada al concepto de cuerpo como "valor intercambiable»; en consecuencia, el interés por aquélla está directamente relacionado con las oportunidades de provecho material o simbólico que pueda proporcionar. Esto le lleva a afirmar que hay unas clases sociales más conscientes que otras, debido precisamente a su situación social, del "valor» de un cuerpo sano y bello, y más dispuestas a invertir tiempo y dinero en prácticas gimnásticas.

Concretamente, señala, son las clases altas las que conceden mayor tiempo y dinero a la consecución de un "estar en forma», orgánica y estéticamente hablando, puesto que son las más conscientes de su valor simbólico y de intercambio. En este sentido, las clases medias y bajas, en su deseo de emular a las clases más privilegiadas, entrarían en el «mundo» del deporte y de las gimnasias como medio para acceder simbólicamente a las mismas prácticas que las clases altas.

Aquí surge, desde nuestro punto de vista, una crítica a este modelo teórico: resulta excesivamente rígido. Es difícil hablar hoy día de la extensión de unas prácticas culturales sin tener en cuenta la influencia de los medios de comunicación en la difusión de valores culturales propios de una sociedad de consumo. Es decir, valores tales como la importancia del cuerpo, de una apariencia exterior de acuerdo con los «cánones», de búsqueda de un bienestar corporal y psiquico, no pueden considerarse privativos de un grupo o clase social. Hay diferencias que son fruto de distintos elementos, como la capacidad económica o la concepción del ejercicio fisico, en la forma - tipo de gimnasio, vestimenta, etc. - en que cada grupo social accede a las prácticas gimnásticas.

Por otro lado, podemos aceptar como posición teórica, y hasta cierto punto contrapuesta a la anterior, la tendencia del «hedonismo cultural». Según el sociólogo francés Lipovetsky (1983), vivimos una época donde se democratiza el hedonismo ya existente entre las clases burguesas en el siglo XVIII. Lo que denomina la "revolución neo-individualista» es una vuelta al sujeto, a la persona que se busca a sí misma (y por eso el auge de la psicología), y que descalifica todo lo que va en contra del hedonismo individual. 
En el caso de las prácticas gimnásticas, su auge se explicaría por ser expresión clara de ese deseo individual de búsqueda personal, de acercamiento al placer a través del propio cuerpo, y de la aceptación del cuerpo como sujeto que se exhibe en su belleza, juventud y desnudez.

La primera postura, por excesivamente rígida o determinista, y la segunda por un exacerbado individualismo, no explican enteramente el fenómeno, aunque sí nos ayudan a interpretar el auge de las gimnasias de la forma en toda su complejidad.

Asimismo, resulta relevante tener en cuenta recientes interpretaciones de sociólogos norteamericanos sobre esta manifestación de la «búsqueda de la forma». Autores como B. Johnson y B. Philips (1985), A. Klein (1986), W. E. Thompson y J. H. Bair (1982) han analizado ciertas prácticas gimnásticas como el culturismo o el aerobic, en términos de "subcultura», fundamentalmente desde una perspectiva etnográfica o interaccionista-simbólica. Así pues, se encontrarían en dichas prácticas elementos que permitirían definirlas como «subcultura»: un lenguaje o "argot» determinado, la vestimenta, los accesorios (cinturones, cintas, etc.), una jerarquía interna en la sala (en el caso de la musculación) y ciertas funciones sociales, unas manifiestas (mejora del tono del músculo, pérdida o aumento de peso) y otras latentes (disminución del "estrés», aumento de la autoestima).

Finalmente, hay autores, también norteamericanos, como Edgely y Turner (1982) que han interpretado el fenómeno del aerobic como una "metáfora religiosa». El aerobic u otras gimnasias «de la forma» podrían llegar a considerarse una «nueva religión» en el sentido amplio del término: un sistema de creencias, prácticas y valores éticos con una significación «sagrada» para las personas que las practican. Detallando algo más los términos de la comparación, el aerobic tendría sus "gurús» o «sacerdotes-isas» que preconizan las ventajas de su práctica, la "conversión» personal se expresa en términos de cambio de identidad: las personas hablan del «antes» y el «después» de conocer el aerobic.

Parece tratarse de una interpretación aplicable a la sociedad norteamericana, sociedad por excelencia del «hacerse a sí mismo", donde "todo puede conseguirse» con el esfuerzo personal, y parece posible que se desarrolle esta experiencia de autodisciplina y creencia absoluta en el esfuerzo individual para la consecución de un ideal; pero en la sociedad española predomina la ética judeo-cristiana, donde el individuo no tiene tanta autonomía frente a los designios divinos y la iniciativa individual no es vivida como algo obligatorio.

Los modelos explicativos anteriormente nos muestran las posibilidades de estudio de un fenómeno que en principio pudiera parecer banal y falto de contenido sociológico, además de demostrarse que ha sido objeto de reflexión por un cierto número de sociólogos en diferentes países. 


\section{EL DESARROLLO DE LAS GIMNASIAS DE LA FORMA EN ESPAÑA}

A lo largo de los años ochenta se produce en España, al igual que en el resto de países occidentales, la extensión y desarrollo de las gimnasias «de la forma». La publicación en España del conocido libro de Jane Fonda En Forma, en 1983, marca el auge de estas actividades, que a partir de esa fecha, pueden encontrarse en prácticamente todo tipo de gimnasios, públicos y privados.

Lo primero que observamos es una multiplicidad y variedad de técnicas que a veces se superponen. A partir de un «tronco común» se han desarrollado métodos casi personales, pero que, no obstante, se pueden agrupar y analizar en función de una serie de características.

En las gimnasias en estudio podemos diferenciar tres grupos según su "procedencia» o influencia predominante:

1. Gimnasias influenciadas fundamentalmente por los nuevos métodos americanos (californianos): aerobic, gim-jazz.

2. Gimnasias influenciadas por filosofías o religiones orientales: yoga.

3. Gimnasias influenciadas o derivadas de la corriente «neosueca»: gimnasia de matenimiento, musculación (que, en su nueva versión, Bodybuilding, tiene influencias norteamericanas).

Todas estas gimnasias se han adaptado en cierta forma a la idiosincrasia española y en muchos casos, como señalábamos anteriormente, se han mezclado entre sí produciendo métodos personales.

En un intento de análisis de estas prácticas podemos hacer una clasificación según los siguientes rasgos: importancia del aspecto lúdico versus ascético y, por otro lado, búsqueda de la mejora de la apariencia versus equilibrio interior (bienestar psíquico), elementos con los que configuramos el siguiente «espacio» de las posiciones de las diferentes prácticas gimnásticas. Este análisis se basa en las informaciones recogidas a través de la observación participante realizada y de las entrevistas en profundidad, si bien queremos hacer la matización de que, al tratarse de actividades en continuo cambio, la interpretación debe hacerse dentro del contexto temporal y espacial de nuestro estudio ${ }^{6}$.

El gim-jazz se revelaría como la práctica gimnástica con mayor contenido lúdico junto con el aerobic, aunque este último aparece más definido por la consecución de la apariencia deseada. En el extremo opuesto, el yoga, que se caracteriza esencialmente por la búsqueda de un equilibrio interior, pero también en gran parte descargado de elementos ascéticos. La gimnasia de manteni-

${ }^{6}$ El trabajo de campo que constituye la base de este estudio se desarrolló de 1987 a 1989. Consistió en tres grupos de discusión, 18 entrevistas en profundidad, observación participante en varios gimnasios y 250 entrevistas mediante cuestionario estructurado a practicantes de las gimnasias consideradas en 14 gimnasios madrilenos. 


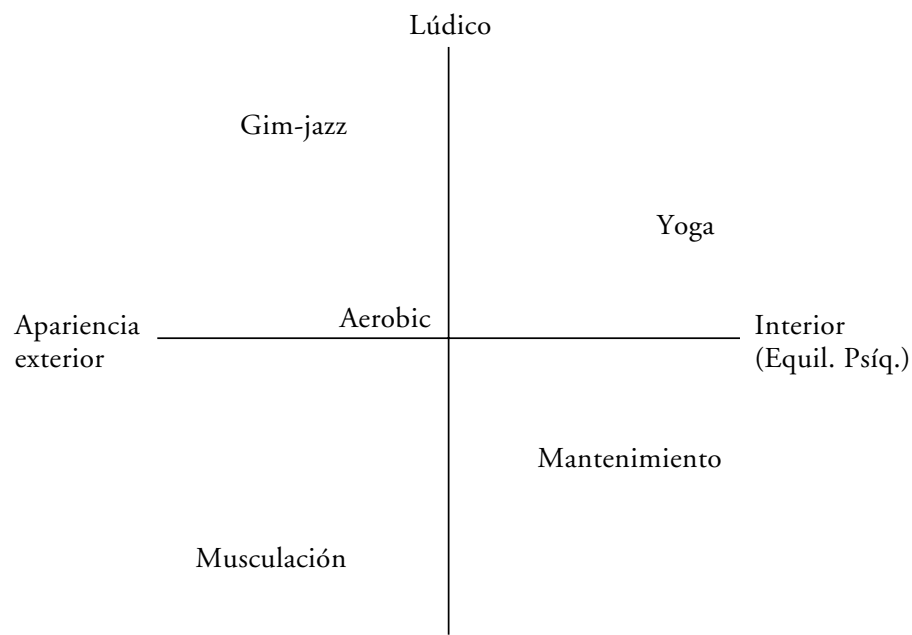

Ascético

miento fluctuaría entre los cuatro polos. Y, por último, la musculación se sitúa claramente en la vertiente ascética y con voluntad de modificar la apariencia física.

En todo caso, aparecen dos características comunes a este grupo de actividades gimnásticas, sobre todo teniendo en cuenta la consideración que los propios sujetos hacen de su práctica.

En primer lugar, el carácter lúdico que en mayor o menor medida aparece en todas las gimnasias, y que lo distigue de la gimnasia «tradicional». El "pasárselo bien", el divertirse, a la vez que se "trabaja», ha pasado a ocupar un lugar importante en la justificación personal. Así se refleja en la opinión de una de las entrevistadas:

«La gimnasia era una asignatura dentro de las que tenías en el colegio, y entonces era una asignatura bastante rollo, porque se limitaba a eso, un saltito..., a unos ejercicios muy monótonos. Ahora la gente que da, o sea, los monitores, están mucho más preparados que estaban antes. Te hacen una gimnasia mucho más entretenida, mucho más divertida, más lúdica» (Mujer. 40 años. Ama de casa. Practicante de aerobic).

En segundo lugar, la consideración de la práctica de una gimnasia como una mejora en la calidad de vida, frente a la consideración como mero fenómeno de "moda" pasajera. En el cuestionario, que forma parte del trabajo de campo realizado, se recogía la opinión respecto a este punto: el acuerdo en considerar la actividad gimnástica como un elemento de mejora de la calidad de vida es casi unánime: el 92 por 100 de los encuestados así lo afirman, sin 
grandes diferencias según el sexo y la actividad que practican, y con un ligero aumento según se incrementa la edad (véase cuadro 1).

En cuanto a la consideración como un fenómeno de moda, los porcentajes más elevados, pero que en ningún caso llegan al tercio de los encuestados, se encuentran entre los más jóvenes (18-24 años) y quienes practican musculación.

\section{CUADRO 1}

Consideración de la actividad gimnástica. Porcentajes (Respuestas independientes)

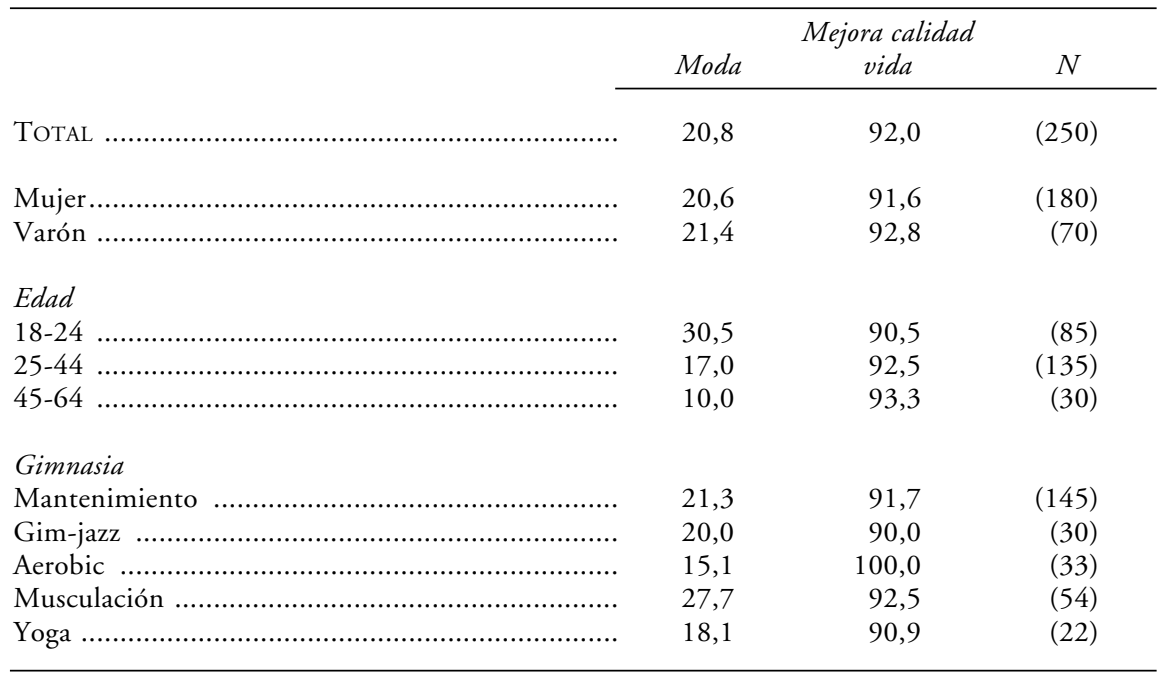

FUENTE: Elaboración propia.

Asimismo, existen diferentes percepciones del propio cuerpo relacionadas con la actividad gimnástica que se practique. La elección de una gimnasia u otra implica una específica relación con el propio cuerpo, una búsqueda corporal diferente. Los practicantes de yoga se expresan en términos de «equilibrio corporal», una relación "amable» con su cuerpo, donde se rechaza el dolor y los movimientos deben ser «relajados y profundos».

Así nos relataban los practicantes de yoga su vivencia corporal:

«Para mí, el yoga supone otra concepción del cuerpo que la gimnasia. El yoga te enseña a hacer movimientos profundos y relajados. Además, si no lo haces relajado, te hace daño... Hay que sentir los límites de tu cuerpo, y dejarlo ir...» (Varón. 42 anos. Casado con dos hijos. Administrativo). 
«Me supone una relajación total. Con las tensiones de cada día... no es lo mismo que sentarse y cerrar los ojos... Es decir, solamente pensar en la respiración que pasa en tu cuerpo, cada músculo, uno detrás de otro, es verdaderamente pensar en el interior de tu cuerpo, lo que no haces nunca en tu casa», (Mujer. 52 años. Casada, con dos hijos. Funcionaria).

Los practicantes de una gimnasia más dinámica, como la gimnasia de mantenimiento o el aerobic, buscan equilibrar cuerpo y mente, compensar la vida sedentaria y mejorar o mantener la figura. Así nos los manifestaba una practicante:

«Por mi parte, cuando se hace un trabajo de tipo intelectual, siempre delante de una mesa como yo, entonces para reestablecer el equilibrio es muy importante hacer una actividad física, hacer ejercicios. Y por el físico, también, claro, es importante verse bien» (Mujer. 22 años. Soltera. Estudiante. Aerobic).

Para los practicantes de musculación, la percepción corporal está centrada en la apariencia, con una finalidad estética pronunciada. Un gimnasta afirmaba lo siguiente:

«La musculación es sobre todo para hacer un cuerpo bello, bien formado. No es obligatorio que si se envejece haya que perder la forma, el cuerpo... se puede guardar, guardar la salud, la actividad, la belleza... las mujeres y los hombres» (Varón. 34 años. Divorciado. Periodista).

En cierto modo persisten las diferencias según género. Así pues, los varones representan una minoría en las actividades grupales de aerobic, gim-jazz, yoga, y una mayoría en musculación, actividad ésta individual y de marcada finalidad estética. Es decir, por un lado, el que los varones reconozcan la importancia de la belleza corporal aparece como un elemento nuevo, pero, por otro, lo hacen mayoritariamente a través de una actividad específica - musculación-, en la que predomina la fuerza y el esfuerzo, y realizada con sofisticadas máquinas, lo que podría considerarse relacionado con características masculinas.

Las diferencias según la edad son bastante evidentes: las jóvenes buscan liberar una energía, mantener la agilidad y conseguir un modelo corporal determinado, mientras que entre las mujeres adultas es más frecuente la búsqueda de un equilibrio psicofísico, relajación y/o mejorar ciertos problemas de salud, incluso el hecho de "dedicarse» un tiempo a una misma, que se ve como algo nuevo e importante. Los siguientes fragmentos de entrevistas así lo manifiestan: 
«Está muy bien moverse verdaderamente, sentirse así... y además es una relajación. El trabajar el cuerpo así hace que te olvides de los problemas, las inquietudes, la rutina, todo eso... Entonces yo encuentro... que ya el hacer algo por una misma es muy importante." (Mujer. 40 años. Casada, con tres hijos. Ama de casa. Gimnasia de mantenimiento).

«... para tener un cuerpo más firme, tener una silueta, no delgada, pero estar bien. Y yo encuentro que me da energía, entonces, estoy de mejor humor, duermo mejor. Yo creo que es un poco la salud y un poco la belleza» (Mujer. 22 años. Soltera. Estudiante. Aerobic).

También en las entrevistas obtenemos «testimonios» de los cambios experimentados en la concepción del cuerpo y el ejercicio físico por las mujeres adultas:

«Antes no se podía hablar de disfrutar del cuerpo, relajarse, o por lo menos, aunque se pensaba, no se decía. Antes, el disfrutar era sentarse, lavarse... ahora vivimos con un confort... que ya no son los mismos valores» (Mujer. 55 años. Casada, con dos hijos. Pequeña empresaria. Gimnasia de mantenimiento).

«Pues yo creo que ha habido un cambio grandísimo. O sea, yo parto de la base de que eso nos habría gustado a todas en nuestra edad, y a mi madre y a mi abuela. Porque me parece estupendo que disfruten de la vida, del cuerpo y de todo. Y con respecto a la gimnasia, también ha habido un cambio grandísimo. Antes era obligatorio y a la pura fuerza; ahora es un hobby. O sea, ha cambiado muchísimo la mentalidad, en general» (Mujer. 45 años. Casada, con cuatro hijos. Ama de casa. Aerobic).

En este caso resulta relevante el constatar cómo para mujeres, amas de casa, el poder salir del hogar para desarrollar una actividad que implica relación social y tiempo "para una misma», ha tenido consecuencias casi terapéuticas.

La visualización del propio cuerpo y del de los demás en el espejo de la sala de gimnasia es una experiencia ambivalente: se toma conciencia del propio cuerpo, de sus límites, defectos y bondades, en una comparación con los demás, por lo que al mismo tiempo el individuo se vuelve sujeto - con identidad propia, que se mueve, decide-, y por otro, su identidad se diluye en el grupo, que imita las acciones del profesor.

"Algo que es muy importante — nos decía una joven practicante de aerobic - es llegar a mirarse en el espejo. Es muy duro mirarse en el espejo, porque ves todos tus defectos... Y seguramente esté bien, porque aprendes, creo yo, a aceptarte como tú eres» (Mujer. 22 años. Soltera. Estudiante. Aerobic). 


\section{CONSIDERACIONES FINALES}

Las gimnasias de la forma y los modelos corporales que conllevan pueden sintetizarse en torno a dos posturas:

- Un primer modelo «instrumental», de eficacia, de "éxito personal», donde destaca la voluntad de actuar sobre uno mismo. Se corresponde con un cuerpo energético, eficaz, donde la fuerza y la belleza son valores importantes. En cierto modo es el modelo tradicional masculino, pero que para las mujeres supone una gran novedad y la entrada en un «mundo público» hasta ahora reservado a los varones. Es el modelo más difundido actualmente con las gimnasias «de la forma», a excepción del yoga.

- El segundo modelo, que denominamos «relacional», está dominado por la relevancia de los aspectos lúdicos y de relación social, así como por el deseo de construir espacios de comunicación opuestos a una lógica instrumentalista. Aquí el cuerpo es fundamentalmente un medio de expresión, de comunicación, olvidándose en gran medida la búsqueda del modelado corporal a favor del mantenimiento o la búsqueda de la salud y de la relación social.

Ambos modelos coexisten en la sociedad actual y tanto mujeres como varones optan en función del valor simbólico que otorgan a su cuerpo y al de los otros, esto, evidentemente, relacionado con el género, el medio social de pertenencia y la influencia de los medios de comunicación.

Las gimnasias de la forma nos ayudan a comprender el significado del cuerpo en la sociedad actual, donde se ha convertido en un importante elemento comunicador y en un símbolo de modernidad. 


\section{REFERENCIAS BIBLIOGRAFICAS}

BaUdrillard, Jean (1985; 1. a ed., 1974): La société de consommation. Ses mythes, ses structures, París, Ed. Gallimard, Col. «Idées».

- (1976): L'echange symbolique et la mort, París, Ed. Gallimard.

- (1981): Simulacres et simulation, París, Ed. Galilée.

Bell, Daniel (1976): Las contradicciones culturales del capitalismo, Madrid, Ed. Alianza Universidad, Col. «Ciencias Sociales».

- (1980): El advenimiento de la sociedad postindustrial, Madrid, Ed. Alianza.

BIRDWHISTELL, R. L. (1972): Kinesics and context: essays on body motion communication, New York, Ed. Ballantine.

BoltanSKi, Luc (1971): "Les usages sociaux du corps», en Annales d'Economie, Société et civilisation, n. ${ }^{\circ} 1$, janvier/fevrier, vol. 26, pp. 205-223.

Bourdieu, Pierre (1988; e.o., 1979): La distinción. Criterio y bases sociales del gusto, Madrid, Ed. Taurus.

- (1980): Le sens pratique, cap. "Rites et marquages du corps: le corps comme memoire sociale», París, Ed. de Minuit.

- (1986): «Notas provisionales sobre la percepción social del cuerpo», en F. Alvarez-Uría, y J. Varela, (eds.), Materiales de Sociología Crítica, Genealogía del Poder, 13, Madrid, Ed. La Piqueta.

- (1987): Cosas dichas, cap. «Programa para una Sociología del deporte», Barcelona, Ed. Gedisa.

Brohm, Jean-Marie (1982): Sociología política del deporte, México, Fondo de Cultura Económica, Sección de Obras de Sociología.

BUÑUel, Ana (1992): La construcción social del cuerpo: prácticas gimnásticas y nuevos modelos culturales, Madrid, Editorial de la Universidad Complutense.

- (1991): "The recreational physical activities of spanish women: a sociological study of exercising for fitness", en International Review for the Sociology of Sport, vol. 26, 1991, 3, pp. 203216.

Cagical, José M. a (1980): "Filosofía del deporte femenino", en Apuntes de Medicina Deportiva, vol. XVII, n. ${ }^{\circ}$ 68, pp. 179-191.

- (1981): ¡Oh deporte! (Anatomía de un gigante), Valladolid, Ed. Miñón, Col. «Kiné de Educación y Ciencia Deportiva».

- (1983): «El cuerpo y el deporte en la sociedad moderna», en Papers: Revista de Sociología, n. ${ }^{\circ} 20$, pp. $145-156$.

Colectivo del Libro de la Salud de las Mujeres de Boston (1984; e.o., 1971): Nuestros cuerpos, nuestras vidas, Barcelona, Ed. Icaria, Col. "Totum Revolutum», cap. 4: "Cómo cuidarnos", pp. 85-95.

Dumazedier, Joffre (1964): Hacia una civilización del ocio, Barcelona, Edit. Estela.

Durán, M.a Angeles (1987): «La práctica del ejercicio físico del ama de casa española. Un estudio sociológico», en Mujer y Deporte, Madrid, Instituto de la Mujer, I Serie «Debate».

Durán, M.a A., et al. (1988): De puertas adentro, Madrid, Ministerio de Cultura, Instituto de la Mujer, Serie «Estudios».

Edgely, Ch., y Turner, R. (1982): «The Rhetoric of Aerobics: physical fitness as Religion», en Free Inquiry, vol. 10, n. ${ }^{\circ}$ 2, noviembre, pp. 187-191.

Elias, N., y Dunning, E. (1992): Deporte y ocio en el proceso de la civilización, México, Ed. Fondo de Cultura Económica.

Featherstone, Mike (1982): «The body in consumer culture», en Theory, Culture and Society, I, pp. 18-33.

- (1987): «Le corps dans la culture de consommation», en Le corps en jeu, Revista Sociétés, n. ${ }^{\circ}$ 15 , septiembre.

Featherstone, M., y Hepworth, M. (1983): «Fitness, body maintenance and lifestyle within consumer culture», en Sports et sociétés contemporaines, VIII Symposium de l'ICSS, París, INSEP, 6-10 julio. 
Featherstone, Mike, et al. (eds.) (1990): The Body: Social process and Cultural Theroy, Londres, Routledge.

Foucault, Michel (1984a): Vigilar y castigar. Nacimiento de la prisión, México, Ed. Siglo XXI.

- (1984b): Histoire de la sexualité, 3 vols.: 1. "La volonté de Savoir», 2. "L’Usage des plaisirs», 3. «Le Souci de soi», París, Ed. Gallimard, Bibliotheque des histoires.

García Ferrando, Manuel (1982): Deporte y sociedad. Las bases sociales del deporte en España, Madrid, M. ${ }^{\circ}$ de Cultura, Dirección General de Juventud y Promoción Sociocultural.

- (1986): Hábitos deportivos de los españoles (Sociología del comportamiento deportivo), Madrid, Instituto de Ciencias de la Educación Física y del Deporte, M.o de Cultura, Consejo Superior de Deportes.

- (1987): "Aspectos sociológicos de la mujer en la alta competición», en VV.AA., Mujer y Deporte, Madrid, Instituto de la Mujer, Serie «Debate».

- (1990): Aspectos sociales del deporte. Una reflexión sociológica, Madrid, Ed. Alianza, Col. «Alianza Deportes».

- (1991): Los españoles y el deporte (1980-1990): Un estudio sociológico, Madrid, Consejo Superior de Deportes.

Gil Calvo, E., y Menéndez Vergara, E. (1985): Ocio y prácticas culturales de los jóvenes, Madrid, Instituto de la Juventud, M. ${ }^{\circ}$ de Cultura, Col. «Informe Juventud en España», n. ${ }^{\circ} 2$.

Goffman, Erving (1981): La presentación de la persona en la vida cotidiana, Argentina, Amorrortu Editores.

Hall, Edward T. (1973): La dimensión oculta. Enfoque Antropológico del uso del espacio, Madrid, IEAL.

Heineman, Klaus (1991): "Tendencias de la investigación social aplicada al deporte», en Politicas Deportivas e Investigación Social, Actas del Congreso, Pamplona, pp. 5-41.

INGLEHART, Ronald (1991): El cambio cultural en las sociedades industriales avanzadas, Madrid, Centro de Investigaciones Sociológicas.

IrIgaray, Luce (1977): Ce sexe qui n'en est pas un, París, Ed. de Minuit, Col. «Critique».

Johnson, B., y Philips, B. D. (1985): «Social functions of the sports subculture: the danceexercise aerobics program», comunicación en la Annual Meeting of the North Central Sociological Association, Mec.

KLEIN, Alan M. (1986): «Pumping Irony: Crisis and contradiction in bodybuilding», en Sociology of Sport Journal, 3, pp. 112-133.

KRAWCZYK, Zbigniew (1983): «The body as a value. Theoretical assumptions and the research problem», en Sports et Sociétés Contemporaines, VIII Symposium de l'ICSS, París, INSEP, 6-10 julio, pp. 463-469.

Lipovetsky, Gilles (1983): L'Ere du vide. Essais sur l'individualisme contemporain, París, Ed. Gallimard.

- (1990): El imperio de lo efimero. La moda y su destino en las sociedades modernas, Barcelona, Ed. Anagrama.

Mauss, Marcel (1966): «Les techniques du corps», en Sociologie et anthropologie, París, Ed. PUF, Col. «Sociologie d'aujourd'hui».

Ortega y GASSET, José (1981; 1. a ed., 1957): El hombre y la gente, Madrid, Revista de Occidente, Alianza Editorial.

- (1988): «Sobre la expresión, fenómeno cósmico», en Obras completas, vol. II, Madrid, Alianza Ed., Revista de Occidente, pp. 577-594.

Thompson, W. E., y BAIR, J. H. (1982): "A sociological analysis of pumping iron», en Free Inquiry, vol. 10, 2, pp. 192-196.

Turner, B. (1989): El Cuerpo y la Sociedad. Exploraciones en Teoría Social, México, Fondo de Cultura Económica.

VÁZQUEZ, Benilde (1987): «Educación física para la mujer: mitos, tradiciones y doctrina actual», en Mujer y Deporte, Madrid, Instituto de la Mujer, Serie «Debate». 


\title{
RESUMEN
}

En este estudio se parte del interés que han despertado en nuestra sociedad, sobre todo entre la población femenina, ciertas actividades corporales relacionadas con la salud, la obtención de una apariencia determinada y con la utilización del tiempo libre en actividades de «mejora de la calidad de vida", como son las "gimnasias recreativas o gimnasias de la forma" (aerobic, gim-jazz, mantenimiento, musculación, yoga). Un estudio detallado de las mismas revela que hay diferencias internas que permiten su clasificación y su relación con diferentes modelos corporales: modelo «instrumental» y modelo «expresivo». Como marco teórico se utilizan los enfoques sobre la utilización del cuerpo de Baudrillard («El cuerpo, el más bello objeto de consumo»), Bourdieu (hábitus de clase y uso del cuerpo), Turner (el cuerpo, blanco de la racionalización moderna), entre los más relevantes. Asimismo, teniendo como punto de partida la relación entre cuerpo y género se revisan otros conceptos como son el ocio y el deporte en la sociedad española actual. La perspectiva teórica se ha completado con un análisis empírico sobre la práctica de gimnasias y su relación con la consideración del cuerpo por parte de las mujeres en España.

\begin{abstract}
This study begins from the interest that has been aroused in our society, especially in the female population, by certain physical activities related to health, the attainment of a determinated appearence and the use of free time in activities which improve our "quality of life», like, for example, «recreational gymnastics, or fitness gymnastics» (aerobics, gym-jazz, keep fit, body building, yoga). A detailed study of these reveals that there are internal differences which allow them to be classified and related to different body models: the "instrumental» model and the «expressive» model. The theoretical framework utilizes the approaches on the use of the body by Baudrillard ("the body, the most beatiful consumer product»), Bourdieu ("Class habitus and use of the body»), and Turner («the body, target of modern rationalization»), among the most prominent. At the same, other concepts like leisure and sport in present-day Spanish society are reviewed taking as a starting point the relationship between body and gender. The theoretical perspective is complemented by an empirical analysis of the practice of gymnastics and its relationship to how women in Spain consider their bodies.
\end{abstract}

